\title{
Optimisation modelling for gas supply in Eastern Australia
}

\author{
J. Plummer ${ }^{\mathrm{a}}, \underline{\text { S. Schreider }}{ }^{\mathrm{a}}$, and D. McInnes ${ }^{\mathrm{b}}$ \\ ${ }^{a}$ School of Mathematical and Geospatial Sciences, RMIT University, Melbourne, Victoria \\ ${ }^{b}$ School of Mathematical Sciences, Monash University, Clayton, Victoria \\ Email: Sergei.Schreider@rmit.edu.au
}

\begin{abstract}
The security of gas supply is a crucially important question for economic of any country. Southeastern Australia has a sophisticated network of gas pipelines which connect the productions sites in the ocean shelf and in the inner part of the continent with major consumers which are capital cities (Adelaide, Melbourne, Hobart, Sydney and Brisbane) and major seaport of Gladstone in Queensland where gas is liquefied and then shipped to the Asian market. Two optimisation models were developed in order to test the satisfied demand security of the gas supply system to the possible global impacts which affect the demand for natural gas. The modelling research in the present work was focused on the simulation of delivery when demands reach their peak values. The first model minimises shortfalls in major supply nodes. As major constrains models used the production levels, supply capacities and mass balance in pipe junctions. The second model minimises the total cost of the gas delivery, which is a sum of production and transportation costs, whereas the constraints mostly stay the same. Both models were run for a series of the plausible economic scenarios which generated the future values of demands. The potential "bottle necks" in the system components were identified. It was found that the first constraint which became scarce is the pipe providing gas to the port of Gladstone. The capacity of this pipe should be increased in order to facilitate the increase of export from Gladstone, but will reduce supply to other consumption nodes.
\end{abstract}

The first model focused on the shortfall minimisation can be considered as a decision support tool for gas delivery reallocation. It can help relevant authorities to obtain maximum security (or minimal risk) in the gas delivery network system, which is treated as elimination of problem related to the gas supply shortfalls for the time when demand level reach their peak values. Despite of simplifications admitted in this model it should be noted that it is a first step in the direction of risk management for the gas supply in South-eastern Australia. In present formulation the equal penalties are assigned to shortfalls in all demand nodes. This is the major problem associated to the shortfall minimisation model. At present there is no information available which would make possible the differentiated approach to the shortfalls in different demand nodes. This could be one of potential directions of future research work.

The second model formulated in the present work minimises the cost of supplying gas to consumers. The model includes both the cost of production and the cost of transportation. Much of the research on gas transportation focuses solely on transportation costs and neglects the cost of production. However, the cost of production is highly variable across gas basins, and even across fields within the same basin. Natural gas is often found with heavier hydrocarbons such as propane or butane, and with liquid hydrocarbons like crude oil, with the gas often being the least valuable product. This can mean that natural gas is essentially a byproduct of production with little value. Therefore the variability of production costs is of interest to owners of transmission pipelines, who may see the volume transported through their pipes decline if production costs rise and large gas users find alternative sources of supply. It is also of interest to industries that may be appraising different regions for the construction of new plants, factories, or gas generators.

The sensitivity analysis was implemented for both formulations of the model. The objective was to examine how the key indicators of system security and pipelines' flow were impacted by the changes (increase and decrease) in peak demands. For this sensitivity test the predicted annual scenarios for peak demand increase for four states (ACT was treated as part of NSW in present work) were used. For the analysis of the decrease of demands the equal proportional changes in demand were used for all demand nodes. It can be concluded that under current infrastructure the most vulnerable components of the system are industrial gas users in Galdstone and Mt. Isa (both in Queensland), whereas amongst the domestic consumers it is Brisbane. This conclusion can be utilised in further decision on the pipeline infrastructure upgrade.

Keywords: $\quad$ gas supply, linear programming, quadratic programming, network optimisation 


\section{INTRODUCTION}

As the demand to the natural gas increases in both domestic and industrial sectors the optimal management of natural gas delivery from producers to the consumer is crucially important question for the modern economic development for the majority of the countries. The security of the system is under pressure when demands reach their peak values. These peak values could be different for the summer and winter seasons. The reliability of the pipeline supply systems is tested in these very periods when demands reach their peaks. These peak demands are usually related with the temperature extreme either very cold or very hot weather. Therefore, instead of modelling the gas delivery for moderate demands the peak demands were used as a system input.

A basic introduction to the optimisation of the gas pipeline system is given in Rios-Mercado (2002). A detailed model of the European natural gas market has been constructed by Egging et al. (2008). The model includes gas exports by pipeline to the European market, liquefied natural gas (LNG) exporters located worldwide, gas producers and their marketing arms, dubbed traders", pipeline and storage operators, and consumers in the residential/commercial, industrial and power generation sectors. Optimisation problems are formulated for each of the participants in the market with market clearing conditions defined to link them. Gabriel et al. (2005) produced a similar linear complementarity model of the North American gas market.

Steinbach (2007) approaches the same problem of minimising gas transportation costs by minimising gas consumed by compressors while providing usable solutions that can be used as a tool to aid the network operator in real time. The proposed solution is a model that treats the dynamic equations for the network elements as discrete in a similar manner to Mahlke et al. (2010). They were able to implement an algorithm that can solve the system of discretised partial differential equations with an improvement on the speed and amount of memory needed by the public domain algorithms currently being used. Kolb et al. (2007) approach the fuel minimisation problem as a non-linear mixed-integer problem and use techniques from discrete optimisation.

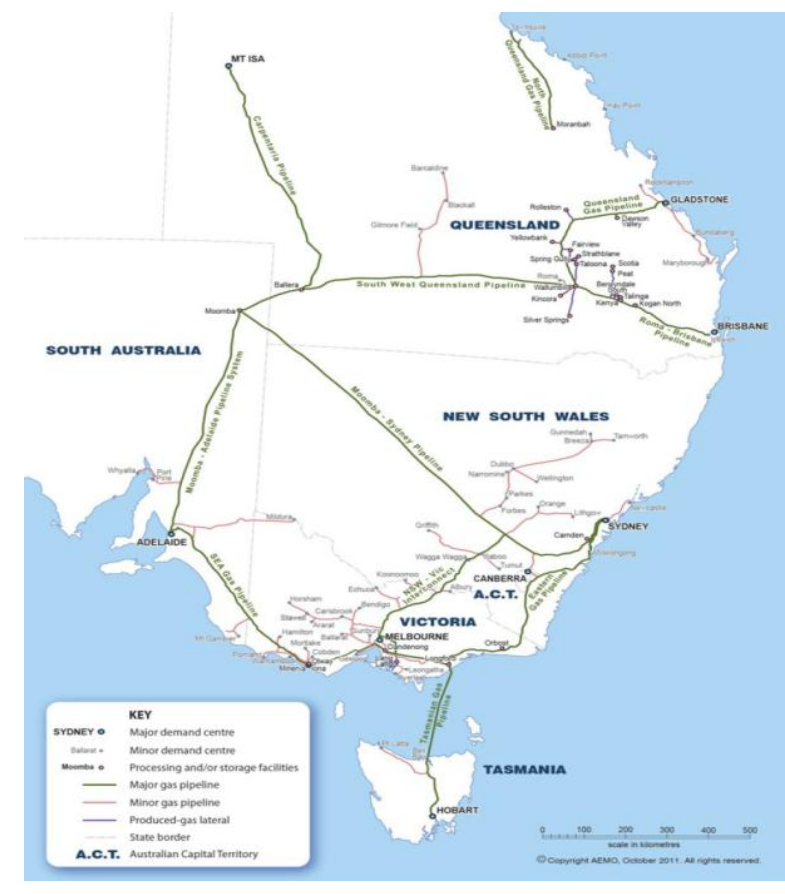

Figure 1. Gas supply system for South-eastern Australia

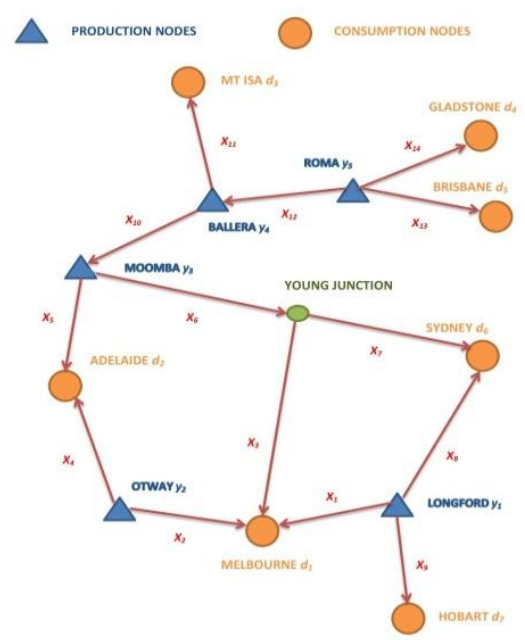

Figure 2. Stylised network representation of this system

There are several optimisation problems of interest when modelling the Eastern Australian gas network however little has been published. With the increasing demand for natural gas the capacity of the network to meet this demand is worthy of analysis. The major transmission pipelines are owned and operated by specialist companies that do not provide operational data readily, therefore modelling relies on the data provided by the market operator. There is surprisingly little research published on optimisation of gas supply 
in Australia, possibly because the problem has been the province of commercial structures rather than academic researchers. For instance, while the ACIL Tasman Company announces the existence of the GasMark model (www.aciltasman.com.au/gasmark) the description of the model is not presented on the company's website and no references were provided. A linear programming (LP) based optimisation technique is being used for practical operations by Australian Energy Market Operator (AEMO). Read et al. (2012) describes the LP model for clearing of the natural gas market in Victoria. The model was initially developed for New Zealand electricity market (Alvey at al., 1998). The gas model presented in these works uses quite complicated flow dynamic approach for approximating the gas transportation over pipeline system. This model is then linearised and solved using LP technique, where decision variables are the physical parameters of the model and constraints are defined by the linearised fluid dynamics equations as well as the limits for upper and lower allowable pressures in the pipes. With more technical details model was described in the companion paper of Papper et al. (2012).

In current work the purely economic optimisation model for regional gas supply was presented. The physical processes were considered exogenously, via capacity constraints of the pipe segments and gas flow directions. The model focuses on the production and delivery costs and capacity constraints of the pipes only. As decision variables the transported amounts of gas and production levels were used.

\section{DESCRIPTION OF THE GAS SUPPLY SYSTEM IN SOUTH-EASTERN AUSTRALIA}

The natural gas supply system is presented in Figure 1, which was reproduced by courtesy of Australian Energy Market Operator (AEMO, 2012). This is a simplified scheme of gas supply which ignores minor pipes constituting the gas supply within production and supply nodes; it indicates only major interconnector between supply or production nodes and major consumers which are capital cities and Port of Gladstone from where the LNG is exported to the Asian market.

Table 1: Characteristic of the gas supply network pipelines capacities and tariffs (source: AEMO (2010))

\begin{tabular}{|l|c|c|c|}
\hline Pipeline & Decision variable & Maximum daily capacity $\boldsymbol{q}_{i}(\mathrm{TJ})$ & Tariff $\boldsymbol{c}_{\boldsymbol{i}}(\mathbf{\$} / \mathbf{G J})$ \\
\hline Longford-Melbourne & $x_{1}$ & 1,030 & 0.24 \\
\hline South West & $x_{2}$ & 353 & 0.27 \\
\hline NSW-Victoria interconnect & $x_{3}$ & 90 & 0.41 \\
\hline SEAGas & $x_{4}$ & 314 & 0.73 \\
\hline Moomba-Adelaide & $x_{5}$ & 241 & 0.65 \\
\hline Moomba-Young & $x_{6}$ & 439 & 0.88 \\
\hline Young-Sydney & $x_{7}$ & 439 & 0.88 \\
\hline Eastern Gas pipeline & $x_{8}$ & 289 summer, 291 winter & 1.16 \\
\hline Tasmanian Gas pipeline & $x_{9}$ & 129 & 2.00 \\
\hline QSNLink (Ballera-Moomba) & $x_{10}$ & 384 & 0.96 \\
\hline Carpentaria & $x_{11}$ & 119 & 1.44 \\
\hline South-West Queensland & $x_{12}$ & 385 & 0.96 \\
\hline Roma-Brisbane & $x_{13}$ & 233 & 0.51 \\
\hline Queensland Gas pipeline & $x_{14}$ & 145 & 0.90 \\
\hline
\end{tabular}

Table 2: Characteristics of the production and demand nodes for summer $(\mathrm{S})$ and winter $(\mathrm{W})$

\begin{tabular}{|c|c|c|c|c|c|c|c|c|}
\hline \multirow[t]{2}{*}{$\begin{array}{l}\text { Production } \\
\text { node }\end{array}$} & \multirow[t]{2}{*}{$\begin{array}{l}\text { Cons'nt/ } \\
\text { Variable }\end{array}$} & \multicolumn{2}{|c|}{$\begin{array}{l}\text { Maximum daily } \\
\text { production }(\mathrm{TJ} / \mathrm{d})\end{array}$} & \multirow{2}{*}{$\begin{array}{c}\text { Cost of } \\
\text { production } \\
p_{i}(\$ / G J)\end{array}$} & \multirow[t]{2}{*}{$\begin{array}{l}\text { Demand } \\
\text { node }\end{array}$} & \multirow[t]{2}{*}{$\begin{array}{l}\text { Cons- } \\
\text { traint }\end{array}$} & \multicolumn{2}{|c|}{$\begin{array}{l}\text { Maximum daily } \\
\text { demand (TJ) }\end{array}$} \\
\hline & & $\mathrm{S}$ & $\mathbf{W}$ & & & & $\mathbf{S}$ & $\mathbf{W}$ \\
\hline Longford & $y_{1}$ & 1463 & 1463 & 2.03 & Melbourne & $d_{1}$ & 650 & 1,135 \\
\hline Otway & $y_{2}$ & 786 & 786 & 4.06 & Adelaide & $d_{2}$ & 410 & 345 \\
\hline Moomba & $y_{3}$ & 390 & 336 & 3.79 & Mt. Isa & $d_{3}$ & 120 & 107 \\
\hline Ballera & $y_{4}$ & 100 & 100 & 3.79 & Gladstone & $d_{4}$ & 145 & 168 \\
\hline Roma & $y_{5}$ & 922.8 & 922.8 & 3.28 & Brisbane & $d_{5}$ & 180 & 219 \\
\hline & & & & & Sydney/ACT & $d_{6}$ & 310 & 389 \\
\hline & & & & & Hobart & $d_{7}$ & 50 & 61 \\
\hline Total & & 3661.8 & 3607.8 & & & & 1865 & 2424 \\
\hline
\end{tabular}

Schematically this gas supply system is presented in Figure 2 as an oriented graph. On this scheme the nodes associated with Canberra were merged with Sydney, as only combined data on demand for these two cities were available. This stylised graph of gas supply system accounts five production nodes: two on the ocean shelf (Longford and cape Otway gas fields) and three continental (Moomba, Ballera and Roma). It also has seven demand nodes: capital cities (Melbourne, Adelaide, Brisbane, Sydney and Hobart), one industrial node 
where gas is used for electricity generation (Mt Isa) and port of Gladstone from where the liquefied gas is sold to Asian market. These nodes (vertices of the graph) are interconnected with fourteen pipelines, which were listed in Table 1 together with their maximum daily capacities, tariffs and index number associated to each particular pipeline. The variable $x_{i}$ defines the quantity of gas transferred for the unit of time (day) for each step of optimisation; later in Section 3 it will be defined as a model's decision variable. As the chemical structure of the natural gas is very complicated and sometime quite heterogeneous the transported quantities were measured in energy equivalent - Terajoules (TJ). Table 1 provides data on the pipeline subscripts and maximum daily quantity (MDQ) that can be transported by the pipe. This information was provided by AEMO (2010). Table 2 shows the current daily production capacity of the producing nodes connected to the eastern Australian gas network. Table 2 also provides information on the daily demand for two seasons for major consumption nodes of the system.

\section{MODEL FORMULATIONS}

The present work considers two formulations for optimisation of the SE Australia's gas network. The first one is focused on minimisation of shortfalls and is based on quadratic programming, whereas the second one is classical LP economic cost minimisation formulation when cost is considered as a sum of production and transportation components. As decision variable the amounts of daily gas transportation were selected: $x_{1}, x_{2}$, ..., $x_{14}$ (see Figure 2 and Table 1) for shortfall minimisation formulation. For cost minimisation this set is amended by the production variables $y_{1}, y_{2}, \ldots, y_{5}$, which play role of constraints in the first formulation. Constraints were constituted by four groups:

a) Production constraints (amount of gas delivered form producers cannot exceed the maximum production):

$$
\begin{array}{llll}
x_{1}+x_{8}+x_{9} & \leq y_{1} & (1) & x_{10}+x_{11}-x_{12} \leq y_{4} \\
x_{2}+x_{4} & \leq y_{2} & (2) & x_{12}+x_{13}+x_{14} \leq y_{5}
\end{array}
$$

$x_{5}+x_{6}-x_{10} \leq y_{3}$

Here $y_{i}$ are the maximum levels of production for all 5 production nodes, which are treated as exogenous variables in the first model (shortfall minimisation) and as endogenous decision variables in the second one (cost minimisation). In the cost minimisation these five constraints are presented in form of equations.

b) Demand constraints (supplied gas does not exceed demand, however shortfalls are possible) for the first model are:

$\begin{array}{ll}x_{1}+x_{2}+x_{3} & \leq d_{1} \\ x_{4}+x_{5} & \leq d_{2} \\ x_{11} & \leq d_{3} \\ x_{14} & \leq d_{4}\end{array}$

Here $d_{i}$ are the maximum demands for all 7 demand nodes. Certainly, the model should be run separately for winter and summer. For the second model the constraints (6)-(12) are formulated in form of equations, which means that no shortfalls allowed.

c) The balance constraint at the Young Junction. The transhipment node at Young is where the New South Wales Interconnect and the Moomba-Sydney pipeline intersect. There is no demand and no supply at this node so the flow in must equal the flow out. This constraint is common for both formulations.

$$
x_{3}-x_{6}+x_{7}=0
$$

d) Non-negativity and capacity constraints

$$
0 \leq x_{i} \leq q_{i} \text {, where } i=1,2, \ldots, 14 ; 0 \leq y_{i} \leq r_{i} \text {, (only for the second formulation) where } i=1,2, \ldots, 5
$$

values of $q_{i}$ are maximum pipeline capacities and $r_{i}$ are maximum productions for summer and winter.

The objective function to minimise shortfall in the first formulation in demand is given in a form of quadratic function:

Min: $S(x)=\left(d_{1}-x_{1}-x_{2}\right)^{2}+\left(d_{2}-x_{4}-x_{5}\right)^{2}+\left(d_{3}-x_{11}\right)^{2}+\left(d_{4}-x_{14}\right)^{2}+\left(d_{5}-x_{13}\right)^{2}+\left(d_{6}-x_{7}-x_{8}\right)^{2}+\left(d_{7}-x_{9}\right)^{2}$

For the second model formulation the objective function is a sum of production and transportation costs, where $p_{i}$ are production cost for all five production sites and $c_{i}$ are tariffs for all fourteen pipeline carriers:

Min: $C(x, y)=\sum_{i=1}^{14} c_{i} x_{i}+\sum_{i=1}^{5} p_{i} y_{i}$ 
These quadratic and linear programming formulations were solved using the MATLAB solver separately for summer and winter seasons. Solution and sensitivity to the inputs are described in Section 4 below.

\section{SENSITIVITY ANALYSIS: SHORTFALL MINIMISATION MODEL}

The model was implemented for the current values of demand for natural gas and for series of hypothetical future scenarios. These scenarios were based on the demand growth factors estimated for each state of Australia included in the gas supply system. The annual demand growth factors are taken from a report published by the market regulator (AEMO, 2010). They are 5.4 and $4.6 \%$ per year for summer and winter in Victoria, 1.4 and $0.2 \%$ in SA, 5.1 and $5.1 \%$ in NSW and ACT, 7.4 and 6.3\% in Queensland and 7.3 and $7.9 \%$ in Tasmania.

The scenarios for summer demands for seven demand nodes for next 20 years were generated, assuming the annual increase specified above. The shortfall minimisation model was run 20 times for all these periods and its outputs were analysed below. The major factor the researcher's attention was focused on is the dynamics of shortfalls. Figure 3 (left panel) indicates how the summer shortfalls changed in time for five major domestic consumers, Mt Isa industrial site and port of Gladstone. It can be concluded that in sense of satisfying the summer demand all Eastern Australia capital cities are quite secure except Brisbane. Based on these scenarios, shortfalls in gas supply will begin in Brisbane in five years in future, whereas next region experiencing shortfalls is Tasmania where shortfalls are predicted in 15 years. In same time the industrial sites are much less secure in sense of the gas supply: Mt. Isa experiences minor shortfall even at present, whereas Gladstone is predicted to be in shortage next year.

Similar analysis was implemented to examine changes in the loads of pipelines constituting the system under scenarios mentioned above. Analysis of results of this 20 years run of the model shows that the summer shortfalls in Mt Isa, Gladstone and Brisbane are related to the limited capacities of single carriers connecting these demand nodes with the rest of the systems. These carriers are Carpentaria, Roma-Brisbane and Queensland Gas pipelines $\left(x_{11}, x_{13}\right.$ and $\left.x_{14}\right)$ for Mt Isa, Brisbane and Gladstone, respectively. The capacity of the carriers 11 and 14 are scares resource even in present, and remain scares when demand increases. Other carriers which could potentially be a "bottle neck" of the supply system are NSW-Victoria interconnect $\left(x_{3}\right)$, which connect the Young Junction in Queensland with Melbourne, and the Eastern Gas pipeline $\left(x_{8}\right)$ which connect the Longford production site with Sydney/Canberra node. The Eastern Gas pipeline $\left(x_{8}\right)$ reaches it maximal capacity in year six in the future for summer peaks.

The same numerical experiment was implemented in order to analyse the winter changes in system demands to shortfalls of the supply network. It was found that the security of the system is much more vulnerable during the winter than in summer: shortfalls start earlier and they are significantly larger (Figure 3). The only exception is Mt Isa, where they are predicted to start two years later than in summer. It can be explained by the slightly larger summer demand for this industrial site. Figure 3 (right panel) demonstrates how the winter shortfalls changed in time for five major domestic and two industrial consumers. The winter shortfalls for all domestic users start earlier even for those (Brisbane) whose demands are lower than in summer. Brisbane will have shortfall earlier than other cities, in two years. Melbourne will experience the difficulties with gas supply in the $7^{\text {th }}$ year, Tasmania and Sydney/Canberra in the $11^{\text {th }}$ and $12^{\text {th }}$, respectively. Adelaide doesn't experience shortfalls as well as during the summer peaks.

The changes in the pipeline load due to future changes in winter demand were analysed as well. The capacity of the South-West, NSW-Victoria interconnect, Moomba-Adelaide, Eastern Gas and Queensland Gas pipelines $\left(x_{2}, x_{3}, x_{8}, x_{14}\right.$, respectively) was immediately reached, with present condition demands. The Roma-Brisbane pipeline $\left(x_{13}\right)$ also reaches its full capacity rapidly: in just one year the only pipeline connecting Brisbane with the rest of the system is at capacity. The crucial system deadlock occurs in the $7^{\text {th }}$ year in the future when full capacity is reached for the Longford-Melbourne pipeline $\left(x_{1}\right)$. As the South West pipelines and NSW-Victoria interconnect $\left(x_{2}\right.$ and $\left.x_{3}\right)$ have already reached their full capacity there are no transportation paths to Melbourne with unused capacity, which could increase gas supply to this city. The Carpentaria pipeline $\left(x_{11}\right)$ reached capacity in two years, which is two years later than for the summer period. This might be partially explained by the reduction in winter demand for the Mt Isa industrial site.

\section{SENSITIVITY ANALYSIS: COST MINIMISATION MODEL}

In the formulation, described above in Section 3, production levels are included as decision variables along with the amount to ship through each pipe. Shortfalls are not permitted and the model is run for both the summer and winter seasons. As this model seeks to minimise costs the primary interest is where gas should be sourced from when a demand centre has multiple supply options. In order to eliminate this unfeasibility the negative slack variable has been amended to the Carpentaria $\left(x_{11}\right)$ and Queensland Gas $\left(x_{14}\right)$ pipelines, 
Plummer et al., Optimisation modelling for gas supply in Eastern Australia

which means the presented solutions for $100 \%$ demands cannot be interpreted as a realisation of the practical scenario. Therefore, the sensitivity analysis for this model has been implanted for the decreased peak demands where the feasible solutions were obtained.
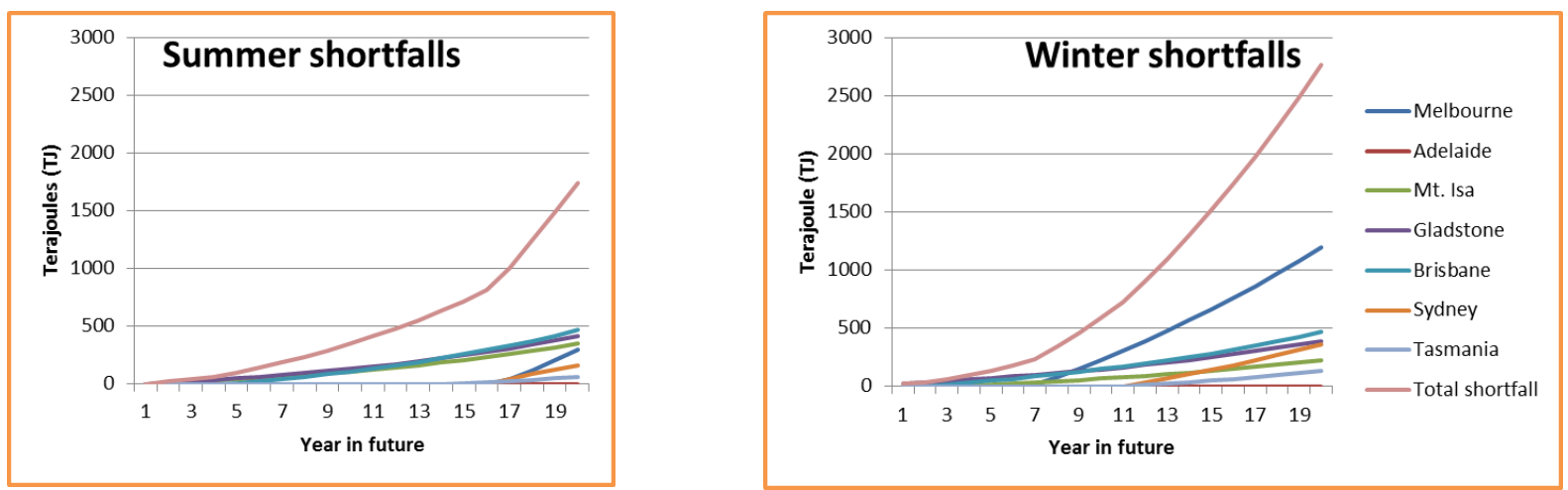

Figure 3. Shortfalls for major demand nodes in the system under increase of demand for summer and winter

Table 3. Sensitivity analysis for minimising the cost of supply in the summer season under demand reduction

\begin{tabular}{|c|c|c|c|c|c|c|c|c|c|}
\hline \multirow[t]{2}{*}{ Pipeline/location } & \multirow[t]{2}{*}{ Variable } & \multicolumn{4}{|c|}{ Summer demand reduction } & \multicolumn{4}{|c|}{ Winter demand reduction } \\
\hline & & $100 \%$ & $90 \%$ & $80 \%$ & $70 \%$ & $100 \%$ & $90 \%$ & $80 \%$ & $70 \%$ \\
\hline \multicolumn{10}{|c|}{ Amount transported TJ/d } \\
\hline Longford-Melbourne & $x_{1}$ & 650 & 585 & 520 & 455 & 1030 & 1022 & 908 & 795 \\
\hline South West & $x_{2}$ & 0 & 0 & 0 & 0 & 105 & 0 & 0 & 0 \\
\hline NSW-Victoria & $x_{3}$ & 0 & 0 & 0 & 0 & 0 & 0 & 0 & 0 \\
\hline SEAGas & $x_{4}$ & 169 & 128 & 87 & 46 & 107 & 70 & 35 & 1 \\
\hline Moomba-Adelaide & $x_{5}$ & 241 & 241 & 241 & 241 & 238 & 241 & 241 & 241 \\
\hline Moomba-Young & $x_{6}$ & 21 & 0 & 0 & 0 & 98 & 59 & 20 & 0 \\
\hline Young-Sydney & $x_{7}$ & 21 & 0 & 0 & 0 & 98 & 59 & 20 & 0 \\
\hline Eastern Gas pipeline & $x_{8}$ & 289 & 279 & 248 & 217 & 291 & 291 & 291 & 272 \\
\hline Tasmanian pipeline & $x_{9}$ & 50 & 45 & 40 & 35 & 61 & 55 & 49 & 43 \\
\hline Ballera-Moomba & $x_{10}$ & 0 & 0 & 0 & 0 & 0 & 0 & 0 & 0 \\
\hline Carpentaria & $x_{11}$ & 129 & 107 & 95 & 83 & 107 & 96 & 86 & 75 \\
\hline South-West Qld & $x_{12}$ & 20 & 7 & 0 & 0 & 7 & 0 & 0 & 0 \\
\hline Roma-Brisbane & $x_{13}$ & 189 & 162 & 144 & 126 & 219 & 197 & 175 & 153 \\
\hline Queensland Gas & $x_{14}$ & 145 & 131 & 116 & 102 & 168 & 151 & 134 & 118 \\
\hline \multicolumn{10}{|c|}{ Amount produced TJ/d } \\
\hline Longford & $y_{1}$ & 989 & 909 & 808 & 707 & 1382 & 1367 & 1248 & 1110 \\
\hline Otway & $y_{2}$ & 169 & 128 & 87 & 46 & 212 & 70 & 35 & 1 \\
\hline Moomba & $y_{3}$ & 262 & 241 & 241 & 241 & 336 & 300 & 261 & 241 \\
\hline Ballera & $y_{4}$ & 100 & 100 & 95 & 83 & 100 & 96 & 86 & 75 \\
\hline Roma & $y_{5}$ & 345 & 300 & 260 & 228 & 394 & 348 & 310 & 271 \\
\hline
\end{tabular}

Table 3 shows the modelling results for minimising the cost of supply in the summer season when demands reduce from $100 \%$ to $70 \%$. The results show the amount of gas transported through each pipe segment and the amount produced at each production node for decreasing percentages of maximum daily demand. The large production capacity and low cost of the Longford plant is the cheapest source to satisfy gas demand in Melbourne. It is also the cheapest way to supply Sydney even though transportation tariffs on the Eastern gas pipeline form Longford to Sydney are among the highest in the network. Higher production costs at the Otway supply node and the excess in production and pipe capacity emanating from Longford in the summer season mean that the South-West pipeline from Otway to Melbourne is idle in the summer. The low demand from Melbourne in the summer relative to the winter means that the New South Wales -Victorian Interconnect, which runs from the Young junction to Melbourne is unused. A similar situation exists in Queensland where the large production capacity at Roma means that Brisbane and Gladstone demand can be satisfied and gas sent west along the South-West Queensland pipeline to Ballera, and then on to Mt. Isa. This leaves the QSNLink from Ballera to Moomba unused.

Table 3 also shows the modelling results for minimising the cost of supply in the winter season. As for summer, the results show the amount of gas transported through each pipe segment and the amount produced at each production node for decreasing percentages of maximum daily demand from $100 \%$ to $70 \%$. Once 
again the low cost production available from Longford is used to supply Melbourne through the LongfordMelbourne pipeline and Sydney through the Eastern gas pipeline. However, the maximum daily quantity that can be transported through the Longford-Melbourne pipeline is insufficient to satisfy demand and higher cost Otway gas is needed on peak demand days. At $90 \%$ of peak demand Melbourne can be supplied with gas from Longford and the South-West pipeline from Otway to Melbourne is unused. The production profile at Otway declines more rapidly in the winter than in the summer season.

6.

\section{DISCUSSION AND CONCLUSIONS}

Two models were described in this paper. The first minimises the shortfalls in simultaneous peak day demand across all demand centres in eastern Australia and applies annual growth factors to each demand centre to model the network over the next two decades. A stable and secure gas supply is a key component underpinning economic growth. This work formulates the gas flow delivery from producers to the demand nodes as a formal network optimisation problem. It was run targeting to satisfy the peak demands in seven demand nodes of Eastern Australia. Two different formulations were considered: the first one which minimises the sum of squares of all shortfalls, and the second one which minimises the integrated cost of all deliveries and productions. The first model focused on the shortfall minimisation can be considered as a decision support tool for gas delivery reallocation in order to obtain maximum security (or minimal risk) in the system. It should be noted that development of this model is a first step in the direction of the risk management for the gas supply in South-eastern Australia. The second model formulated minimises the cost of supplying gas to consumers. The model includes both the cost of production and the cost of transportation. Much of the research on gas transportation focuses solely on transportation costs and neglects the cost of production. However, the cost of production is highly variable across gas basins, and even across fields within the same basin. The variability of production costs is of interest to owners of transmission pipelines, who may see the volume transported through their pipes decline if production costs rise and large gas users find alternative sources of supply. It is also of interest to industry that may be appraising different regions for the construction of new plants, factories, or gas generators. The sensitivity analysis was implemented for both formulations of the model. Both models were examined in order to check how the key indicators of system security and pipelines' flow were impacted by the changes (increase and decrease) in peak demands. This work is an important step toward further, more detailed and complicated, modelling work of the Australian gas supply system.

\section{REFERENCES}

Alvey, T., Goodwin., D., Ma, X., Streifert, D. and Sun., D. (1998) A security-constraint bid-clearing system for the New Zealand wholesale electricity market, IEEE Trans Power Syst 13(2); 340-346.

Australian Energy Market Operator - AEMO (2010, 2012) Gas statement opportunities of Eastern and South Eastern Australia, Executive briefing, and New MIBB report, Melbourne.

Egging, R., Gabriel, S. A., Holz, F. and Zhuang, J. (2008) A complementarity model for the European natural gas market, Energy Policy, 36(7), 2385-2414.

Gabriel, S. A., Zhuang, J. and Kiet, S. (2005) A large-scale linear complementarity model of the North American natural gas market, Energy Economics, 27(4), 639-665.

Kolb, O., Lang, J. and Bales, P. (2007) Adaptive linearized models for optimization of gas networks. PAMM, 7(1), 1061301-1061302.

Mahlke, D., Martin, A. and Moritz, S. (2010) A mixed integer approach for time-dependent gas network optimization, Optimization Methods \& Software, 25(4), 625-644.

Pepper, W., Ring, B.J., Read, E.G. and Starkey, S.R. (2012) Implementation of a scheduling and pricing model for natural gas. In: Sorokin, A., Rebennack, S. and Pardalos, P.M. (eds.) Handbook of networks in Power Systems II, Springer Berlin Heidelberg Dordrecht, pp. 3 - 35.

Read, E.G., Ring, B.J., Starkey, S.R. and Pepper, W. (2012) An LP based market design for natural gas. ibid: pp. $77-113$.

Rios-Mercado, R. Z. (2002) Natural gas pipeline optimization, In: Pardalos P.M. and Resende M. G. C. (eds) Handbook of applied optimization, Oxford University Press, New York, pp. 813-826.

Steinbach, M. C. (2007) On PDE solution in transient optimization of gas networks, Journal of Computational and Applied Mathematics, 203(2), 345-361. 